\title{
Harvesting of Mouse Embryos at 0.5 Dpc as a Tool to Reduce Animal Use: Data from C57BL/6J, B6*129 and FVB/NJ Strains
}

\author{
Sofia Lamas ${ }^{1,2,3 *}$, Filipa Franquinho ${ }^{1,2,3}$, Marlene Morgado ${ }^{1,2,3}$, Fátima Gartner1,2,4,5, \\ Irina Amorim1,4,5 \\ ${ }^{1}$ Institute for Research and Innovation in Health, (i3S), University of Porto, Porto, Portugal \\ ${ }^{2}$ Animal Facility, i3S/IBMC, Porto, Portugal \\ ${ }^{3}$ Institute for Molecular and Cell Biology (IBMC), Porto, Portugal \\ ${ }^{4}$ Institute of Molecular Pathology and Immunology of the University of Porto (IPATIMUP), Porto, Portugal \\ ${ }^{5}$ Department of Pathology and Molecular Immunology, Institute of Biomedical Sciences Abel Salazar (ICBAS), University of Porto, \\ Porto, Portugal \\ Email: *sofia.lamas@ibmc.up.pt
}

How to cite this paper: Lamas, S., Franquinho, F., Morgado, M., Gartner, F. and Amorim, I. (2020) Harvesting of Mouse Embryos at $0.5 \mathrm{Dpc}$ as a Tool to Reduce Animal Use: Data from C57BL/6J, B6*129 and FVB/NJ Strains. Open Journal of Animal Sciences, 10, 254-265.

https://doi.org/10.4236/ojas.2020.102014

Received: December 27, 2019

Accepted: February 22, 2020

Published: February 25, 2020

Copyright $\odot 2020$ by author(s) and Scientific Research Publishing Inc. This work is licensed under the Creative Commons Attribution International License (CC BY 4.0).

http://creativecommons.org/licenses/by/4.0/

\begin{abstract}
Superovulation is used to stimulate the production and release of large amounts of oocytes in mice by using two hormones that mimic FSH (PMSG) and LH (hCG) effects. Since superovulation can have a negative impact on oocyte and embryo development, this investigation aimed to compare two alternatives for 2-cells embryo collection in order to reduce the number of females and to benefit from the superovulation process. Data from mouse embryo collection from our facility was analyzed to compare the number of 2-cells embryos collected at $1.5 \mathrm{dpc}$ and the number of 2-cells embryos obtained after overnight incubation of 1-cell embryos, collected at $0.5 \mathrm{dpc}$. Genetically modified mouse strains with a similar background (C57BL/6J, B6 $6^{\star} 129$ and FVB/NJ) were analyzed and for strains at a C57BL/6J and $B 6^{\star} 129$ background, the number of 2-cells embryos obtained after incubation was significantly higher when compared to the number of 2-cells embryos collected at $1.5 \mathrm{dpc}$ (1.4-fold and 1.7-fold, respectively). C57BL/6J wild type mice had similar results with a higher number of 2-cells embryos when collection was performed at $0.5 \mathrm{dpc}$ followed by incubation (1.4-fold). These results can help the planning of 2-cells embryo harvesting by reducing the number of females needed for this procedure.
\end{abstract}

\section{Keywords}

0.5 Dpc Embryos, 1.5 Dpc Embryos, Incubation, Superovulation 


\section{Introduction}

Assisted reproductive techniques are widely used in the laboratory animal field, mainly in mice and rats, as a tool to improve reproductive performance and to reduce animal use. Superovulation is a technique used to increase the number of oocytes that each female ovulates by injecting pregnant mare's serum gonadotropin (PMSG) and human chorionic gonadotropin (hCG) at an interval of 46 48 hours to mimic the effects of FSH and LH, respectively [1]. This technique greatly reduces the number of embryo donor females needed for a given purpose and has been optimized by controlling several factors that can affect its efficiency such as the female's weight [2] [3], age [4], hormone dose [2], interval between hormones administration [2] and estrous cycle phase at the time of hormone administration [5]. For rederivation purposes, superovulation is used to increase the number of oocytes released by each female that can then be collected after natural mating at $0.5 \mathrm{dpc}$ (1-cell embryos) [6], at $1.5 \mathrm{dpc}$ (2-cells embryos) [7] or even at $3.5 \mathrm{dpc}$ (blastocysts) [8] for subsequent embryo transfer. Embryo transfer can then be performed at several stages of embryo development using 1-cell embryo [6] [9], 2-cells embryos [6] [7] [9] or blastocysts [8] [10]. Embryo culture can also be part of the process by collecting embryos at $0.5 \mathrm{dpc}$ and cultivating up to a 2-cells or blastocyst stage.

For cryopreservation, collection of embryos at different phases can also be a possibility after superovulation [11]. Both superovulation and embryo culture have advantages and disadvantages. Although superovulation can improve the efficiency of embryo collection by synchronizing females and reducing the number of animals for a given purpose, it can affect oocyte and embryo's quality. Superovulation has been associated with a negative impact on oocytes and embryos by provoking changes in maternal and paternal imprinted methylation [12] [13] [14] and delaying embryonic and fetal development [14] [15] [16] [17] [18]. It has also been associated with alterations in essential proteins involved in regulation and translation of maternally stored mRNA with short poly A tail, such as poly(A)-binding protein (Epab) and poly(A)-binding protein cytoplasmic 1 (Pabpc1) [16] [19]. Important genes can be dysregulated due to superovulation, such as the Mest gene or the Grb10 [20] [21] and regulatory proteins can also be changed by this procedure like STAT3, leptin, transforming growth factor $\beta$-2 among others [22].

Allowing the embryos to grow in utero after a superovulation protocol can attenuate the effect of superovulation by decreasing the number of implantation sites [23], reducing the number of living fetuses [16] [18] as well as increasing pre-implantation mortality [14]. PMSG and hCG stimulation causes changes in the uterine environment that negatively affect embryo and fetal development [18] [24], resulting in reduced litter size and foetal organ's weight [25] [26]. These alterations include changes in lipid metabolism [27] and in NK cells [28], whose regulatory effects on implantation can be compromised. Alterations in the placental blood supply and on genes related with glucocorticoid regulation seem to be one of the responsible mechanisms for the decreased pup's weight [25].

Despite the superovulation disadvantages, this is still an important and needed 
technique for the collection of large amounts of embryos or oocytes.

Embryo culture causes alterations on gene expression patterns of mouse embryos [29] and on the regulation of transposable elements (TE) and M16 media, frequently used for culture, has been associated with an upregulation of these when compared to KSOM [30].

Using embryo culture before the final application, either cryopreservation or embryo transfer, can have practical advantages such as the fact that only fertilized embryos are transferred into a pseudopregnant female or the possibility of splitting the work session in two or more days.

Literature regarding the best time point for mouse embryo collection is sparse and the timing of embryo collection after superovulation and transfer varies between articles. Van der Auwera [23] shows that when embryos are kept longer inside a superovulated oviduct, the number of implantation sites is lower. However, this was only described in a F1 hybrid CBAxC57BL6 background and no information was available regarding the number of embryos harvested at different time points after superovulation.

Since superovulation and incubation of embryos from different genetic backgrounds are common procedures in rodent animal facilities, and there are no standard protocols regarding the time for embryo collection after superovulation, this study may provide useful information about embryo harvesting.

The herein study aimed to explore the possible reduction on the number of embryos collected after a superovulation protocol during the early phases of development if embryos are kept in utero up to a 2-cells stage when compared to collecting the embryos at a 1-cell stage and allowing the passage in the incubator to a 2-cells stage. For that, we analyzed data related to embryo collection from historical data of genetically modified strains at different genetic backgrounds obtained between January 2017 and May 2019 at the i3S Animal Facility and data from C57BL/6J wild type mice.

\section{Materials and Methods}

\subsection{Animals}

The experiments were performed at the i3S animal facility and were reviewed and approved by the internal Animal Ethics Committee and by the Portuguese Competent Authority (DGAV) (project reference 2017_03, June 2017). Animals were housed at the $\mathrm{i} 3 \mathrm{~S}$ animal facility under standard conditions: temperature was kept between $20^{\circ} \mathrm{C}$ and $24^{\circ} \mathrm{C}$ and humidity between $45 \%$ and $65 \%$; donor females were housed in groups of 3 to 4 females in type II eurostandard filter top cages $\left(370 \mathrm{~cm}^{2}\right.$ floor area) for superovulation and then mated with a male, also housed in type II eurostandard cages (males were housed individually during the experimental period); food (2014 Teklad global 14\% protein rodent maintenance diets, 2014S, Envigo Spain) and water (type II distillated) were supplied Ad libitum; bedding material was corncob and enrichment was also provided with a shelter or card tube and paper for nesting material. Animals were free from the following agents: MHV, EDIM, MPV, MVM, PVM, Sendai virus, TMEV, Ec- 
tromelia, LCMV, MAD-1 and 2, Mouse cytomegalovirus, Reovírus, Bordetella bronquiseptica, Citrobacter rodentium, Clostridium piliforme, Corynebacterium kutsheri, Cryptosporidium, Mycoplasma, Pasteurella spp, Pseudomonas aeruginosa, Salmonella spp, Helicobacter spp, Staphylococcus aureus, Streptococcus pneumoniae, Streptobacillus moniliformis, Klebsiella pneumoniae, ectoparasites (Myobia, Radfordia and Myocoptes), Eimeria, Entamoeba, Giardia, Spironucleus muris, Tritrichomonas, Aspiculuris tetraptera and Syphacea obvelata and muris. Occasional positives were found at quarantine for Pasteurella spp, Helicobacter spp, Kebsiella pneumoniae and Staphylococcus aureus as animal origin differs among the two experiments, as explained on the next section.

Data herein presented arose from the collection of mouse (Mus musculus) embryos either for the purpose of embryo transfer (rederivation) or cryopreservation sessions, from January 2017 to May 2019. Data from embryo transfer and cryopreservation sessions are not stated as the aim of this work was to unravel the timing of embryo harvesting. A total of 312 sessions of embryo collection were included in the analysis. Data was grouped according to the genetic background and represent 37 mouse strains of genetically modified mice at a C57BL/6J background, 11 at a mixed background between B6 and SV129 and 6 at an FVB/NJ background housed at the i3S Animal Facility. Another set of experiments was also analyzed using wild type C57BL/6J animals (a total of 2 sessions of embryo harvesting). Animal origin was the $\mathrm{i} 3 \mathrm{~S}$ animal facility (in case the data correspond to embryo harvesting from cryopreservation sessions) or other facilities in case animals were in quarantine (for rederivation purposes). In that case, in quarantine, animals were mated one week after arrival and the litters from that breeding couple were used for superovulation and mating. For each session of GMM, donor females between 3 and 6 weeks of age from each colony were used. Although superovulation tends to work better in younger females, some females at 6 weeks of age were also used in all groups (harvesting at 0.5 and harvesting at $1.5 \mathrm{dpc}$ ) due to the availability of animals and to the fact that females at this age are also described to be used for superovulation [2]. For the C57BL/6J wild type group, females were between 3 and 4 weeks of age. Fertile males (minimum 8 weeks and up to 5 months old) were used. A ratio of 1 female for 1 male was used for mating and males were only used once per week.

\subsection{Superovulation}

PMSG (PMSG, HOR 272, ProSpec) and hCG (hCG, HOR 250, ProSpec) were diluted at a dose of $50 \mathrm{IU}$ in sterile water and frozen at $-20^{\circ} \mathrm{C}$ until further use. Before injection, aliquots were thawed and diluted in sterile water to get a $100 \mu \mathrm{L}$ dosage of $5 \mathrm{IU}$ for intraperitoneal injection.

PMSG and hCG were given at an interval of $48 \mathrm{~h}$. At the time of hCG injection, females were mated with males overnight and checked for plug in the following morning. Only females with plug were considered for the data analysis to ensure that only oocytes with the possibility of being fertilized were being screened and fertilization was not a determinant factor on the result. 


\subsection{Embryo Collection}

For 1-cell embryo collection, females were euthanized the morning after the mating $(0.5 \mathrm{dpc})$ by cervical dislocation. Oviducts were collected in M2 media [31] and digested in M2 supplemented with $0.5 \mathrm{mg} / \mathrm{ml}$ hyaluronidase (Hyaluronidase, H4272, Sigma Aldrich) for less than 1 minute. After digestion, embryos were washed in $50 \mu \mathrm{L}$ M2 drops, followed by several washes in $50 \mu \mathrm{L}$ KSOM drops (EmbryoMax ${ }^{\oplus}$ KSOM Mouse Embryo Media, MR-020P-5F, Sigma Aldrich) and incubated in $50 \mu \mathrm{L}$ drops covered with mineral oil (Mineral oil, M8410, Sigma-Aldrich). A maximum of 50 embryos per drop was incubated at $37^{\circ} \mathrm{C}$ and $5 \% \mathrm{CO}_{2}$. In the following morning, the total number of 2-cells embryos was counted and embryos were then used for cryopreservation or embryo transfer. The initial number of 1-cell embryos was also counted before incubation.

For 2-cells embryo collection, females were euthanized by cervical dislocation at $1.5 \mathrm{dpc}$. Oviducts were collected in M2 media and flushed with the same media through the infundibulum, using a stereomicroscope (Stemi $2000 \mathrm{C}$, Zeiss) and a 30G needle. Two-cells embryos were then counted and washed in M2 media before cryopreservation or embryo transfer on the same day. For the wild type (C57BL/6J) session, the number of non-fertilized embryos obtained at 1.5 dpc was also counted.

\subsection{Statistical Analysis}

Data was analyzed using GraphPad Prism software (version 6.00 for Mac, GraphPad Software, La Jolla California USA). A D’Agostino \& Pearson omnibus normality test was used before comparing 2-cells embryos, plug number and fertility rates. For the GMM strains, data were grouped according to the genetic background of each strain and a Mann-Whitney test was performed to compare the number of 2-cells embryos obtained from females with the same genetic background after incubation or after collection at a 2-cells stage. A Mann-Whitney test was also used to compare the mean number of plugs in each background in sessions using incubation and 2-cells embryos harvesting. For the C57BL/6J wild type session, a t-test was used to compare the mean number of 2-cells embryos and fertility rates. Data are shown as Mean \pm SEM and $p<0.05$ was considered as a statistically significant difference.

\section{Results}

Cryopreservation and rederivation are techniques that rely on collection of multiple embryos to successfully preserve a mouse strain or transfer to a recipient foster female. We started by collecting the data obtained from rederivation and cryopreservation between January 2017 and May 2019 from the genetic backgrounds most widely used in our animal facility: C57BL/6J, mixed background between C57BL/6J and SV129 (B6*129) and FVB/NJ. The number of sessions per genetic background, the number of genetically modified strains and the number of females used in total are summarized in Table 1.

With this data, we aimed at assess whether incubation of 1-cell embryos could 
improve the number of 2-cells embryos obtained for each strain. A statistically significant increase of 1.4 -fold $(\mathrm{p}<0.0001)$ in the number of 2-cells embryos obtained after incubation of $0.5 \mathrm{dpc}$ embryos when comparing to 2-cells embryos collection for C57BL/6J background (Figure 1(a)) was found. Similarly, an increase of 1.7-fold ( $p<0.0019)$ in the number of 2-cells embryos obtained after incubation for strains at a B $6^{*} 129$ background (Figure $1(b)$ ) was observed. For strains with FVB/NJ background, an increase of 1.6-fold in the number of 2-cells embryos was observed after culture when comparing to 2-cells embryos collection (Figure 1(c)) although this observation was not statistically significative ( $\mathrm{p}=$ 0.0698). The mean number of plugs between sessions with the same genetic background was not statistically different for strains with a C57BL/6J and B6* 129 background ( $\mathrm{p}=0.3560$ and 0.5547 respectively). For FVB/NJ background, the mean number of plugs was significantly higher at the incubation group $(p=0.0438)$. Results are summarized in Table 2 and Table 3 for the harvesting at $0.5 \mathrm{dpc}$ followed by incubation and 2-cells harvesting groups, respectively.

Table 1. Number of sessions and females analyzed for the different backgrounds from GMM.

\begin{tabular}{|c|c|c|c|c|c|}
\hline & \multicolumn{2}{|c|}{ Collection at $0.5 \mathrm{dpc}$} & \multicolumn{2}{|c|}{ Collection at $1.5 \mathrm{dpc}$} & \multirow[b]{2}{*}{$\begin{array}{l}\text { Number of } \\
\text { GMM strains }\end{array}$} \\
\hline & $\begin{array}{l}\text { Number } \\
\text { of sessions }\end{array}$ & $\begin{array}{l}\text { Number } \\
\text { of females }\end{array}$ & $\begin{array}{l}\text { Number } \\
\text { of sessions }\end{array}$ & $\begin{array}{l}\text { Number } \\
\text { of females }\end{array}$ & \\
\hline $\mathrm{C} 57 \mathrm{BL} / 6 \mathrm{~J}$ & 64 & 299 & 183 & 926 & 37 \\
\hline $\mathrm{B} 6^{*} 129$ & 12 & 60 & 31 & 167 & 11 \\
\hline $\mathrm{FVB} / \mathrm{NJ}$ & 13 & 97 & 9 & 43 & 6 \\
\hline
\end{tabular}

Number of sessions analyzed for the different backgrounds and number of females used in the total number of sessions according to the method of 2-cells harvesting: collection at $0.5 \mathrm{dpc}$ followed by incubation and collection at $1.5 \mathrm{dpc}$.

Table 2. Data from GMM for 0.5 dpc followed by incubation groups at different backgrounds.

\begin{tabular}{ccccc}
\hline Background & $\begin{array}{c}\text { Mean number } \\
\text { of plugs per } \\
\text { session } \pm \text { SEM }\end{array}$ & $\begin{array}{c}\text { Mean number } \\
\text { of } 1 \text {-cell } \\
\text { embryos } \pm \text { SEM }\end{array}$ & $\begin{array}{c}\text { Mean number } \\
\text { of 2-cells } \\
\text { embryos } \pm \text { SEM }\end{array}$ & $\begin{array}{c}\text { Mean } \\
\text { fertilization } \\
\text { rates (\%) } \pm \text { SEM }\end{array}$ \\
\hline C57BL/6J & $4.672 \pm 0.2826$ & $22.72 \pm 1.383$ & $13.23 \pm 0.9228$ & $59.96 \pm 2.331$ \\
B6 $6^{*} 129$ & $5.000 \pm 0.5222$ & $25.16 \pm 3.351$ & $16.86 \pm 2.716$ & $66.76 \pm 5.689$ \\
FVB/NJ & $7.462 \pm 0.8444$ & $19.88 \pm 3.853$ & $10.02 \pm 1.867$ & $58.88 \pm 8.099$ \\
\hline
\end{tabular}

The mean number of 1 and 2-cells embryos per session is based on the number of embryos obtained divided by the number of females used per session.

Table 3. Data from GMM for 1.5 dpc harvesting groups at different backgrounds.

\begin{tabular}{ccc}
\hline Background & Mean number of plugs \pm SEM & Mean number of 2-cells embryos \pm SEM \\
\hline C57BL/6J & $5.070 \pm 0.2350$ & $9.3 \pm 0.7463$ \\
B6*129 & $5.3870 \pm 0.3953$ & $9.078 \pm 1.731$ \\
FVB/NJ & $4.778 \pm 0.8625$ & $6.377 \pm 1.666$ \\
\hline
\end{tabular}

The mean number of 1 and 2-cells embryos per session is based on the number of embryos obtained divided by the number of females used per session. 


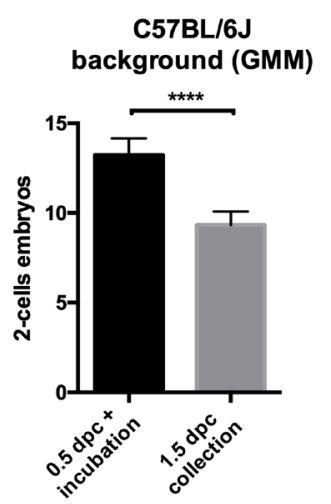

(a)

FVB/NJ background (GMM)

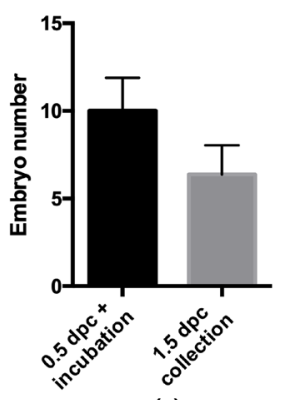

(c)
B6*129

background (GMM)

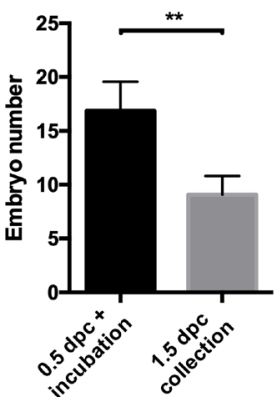

(b)

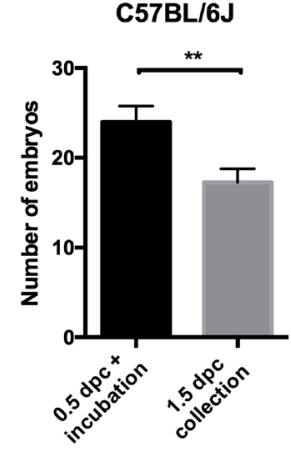

(d)

Figure 1. Mean number of 2-cells embryos obtained from collection at $0.5 \mathrm{dpc}$ followed by incubation and $1.5 \mathrm{dpc}$ collection at different backgrounds. Mean number of 2-cells embryos obtained from GMM or wild type strains using collection at $0.5 \mathrm{dpc}$ followed by incubation and $1.5 \mathrm{dpc}$ collection for: (a) C57BL/6J background (GMM); (b) B6 $6^{\star} 129$ background (GMM); (c) FVB/NJ (GMM) background; and (d) C57BL/6J wild type. Results are expressed as Mean \pm SEM.

When analyzing data obtained through the collection of $0.5 \mathrm{dpc}$ followed by incubation and harvesting at $1.5 \mathrm{dpc}$ from wild type animals (C57BL/6J), the number of 1 and 2-cells embryos was counted for both groups. A significant difference ( $p=0.0093$ ) was found between the mean number of 2-cells embryos collected at $1.5 \mathrm{dpc}$ and at $0.5 \mathrm{dpc}$ followed by incubation. The mean number of 2-cells embryos had an increase of 1.4-fold when incubation of $0.5 \mathrm{dpc}$ embryos is used. No significant difference was found between the two groups fertilization rates $(p=0.1898)$. Data are summarized in Table 4 and Figure $1(d)$ ).

The results herein presented suggest that, to obtain 100 fertilized embryos, we can reduce the number of superovulated females for the majority of the GMM strains analyzed, if the embryos are collected at $0.5 \mathrm{dpc}$ and culture to 2-cells stage. For C57BL/6J, B6 ${ }^{\star} 129$ and $\mathrm{FVB} / \mathrm{NJ}$ strains are required $40 \%, 47 \%$ and $46 \%$ less females, respectively (Table 5). For C57BL/6J wild type animals, similar results are found. In this strain, incubation after $0.5 \mathrm{dpc}$ collection leads to about $33 \%$ less females (Table 5).

Together, these results reinforce that, at least for the backgrounds analyzed, incubation of 1-cell stage embryos can increase the number of 2-cells stage embryos, thus, reducing the number of superovulated females. 
Table 4. Data from C57BL/6J for $0.5 \mathrm{dpc}$ followed by incubation and $1.5 \mathrm{dpc}$ harvesting groups.

\begin{tabular}{cccccccc}
\hline \multicolumn{1}{c}{ Collection at $0.5 \mathrm{dpc}$} & \multicolumn{2}{c}{ Collection at 1.5 dpc } \\
\hline $\begin{array}{c}\text { Mean number } \\
\text { of 1-cell } \\
\text { embryos } \pm \text { SEM }\end{array}$ & $\begin{array}{c}\text { Mean number } \\
\text { of 2-cells } \\
\text { embryos } \pm \text { SEM }\end{array}$ & $\begin{array}{c}\text { Fertility } \\
\text { rate }(\%) \pm \text { SEM }\end{array}$ & $\begin{array}{c}\text { Number of } \\
\text { females }\end{array}$ & $\begin{array}{c}\text { Mean number of } \\
\text { non-fertilized } \\
\text { embryos } \pm \text { SEM }\end{array}$ & $\begin{array}{c}\text { Mean number } \\
\text { of 2-cells } \\
\text { embryos } \pm \text { SEM }\end{array}$ & $\begin{array}{c}\text { Fertility } \\
\text { rate }(\%) \pm \text { SEM }\end{array}$ & $\begin{array}{c}\text { Number of } \\
\text { females }\end{array}$ \\
\hline $41.50 \pm 3.122$ & $24.00 \pm 1.770$ & $59.88 \pm 3.742$ & 22 & $8.813 \pm 1.285$ & $17.25 \pm 1.529$ & $67.09 \pm 3.674$ & 16 \\
\hline
\end{tabular}

The mean number of 1 and 2-cells embryos was obtained individually, per female.

Table 5. Number of females needed for the collection of 100 embryos using the two harvesting methods for GMM at different backgrounds and wild type mice from the C57BL/6J strain.

\begin{tabular}{cccc}
\hline & Collection at $0.5 \mathrm{dpc}$ & Collection at $1.5 \mathrm{dpc}$ \\
\hline \multirow{2}{*}{ GMM } & C57BL/6J & 7 & 12 \\
& $\mathrm{~B} 6^{*} 129$ & 6 & 12 \\
& $\mathrm{FVB} / \mathrm{NJ}$ & 11 & 20 \\
\hline Wild type & $\mathrm{C} 57 \mathrm{BL} / 6 \mathrm{~J}$ & 4 & 6 \\
\hline
\end{tabular}

\section{Discussion}

Superovulation is a technique used to increase the number of oocytes produced and released by female mice. It has the advantage of decreasing the number of females needed for the collection of oocytes or embryos, contributing to the application of one of the 3R's. Despite the potential of this technique, superovulation has many times an uncertain outcome because the number of oocytes released by the female can be low [2] [4] [5] and also the quality of the oocytes or embryos produced after the injection of high doses of PMSG and hCG can be reduced [12] [13] [14] [16] [17] [18] [21] [22] [24] [27] [32] [33]. Our results show that, at least in strains with a C57BL/6J, $\mathrm{B} 6^{\star} 129$ or with an $\mathrm{FVB} / \mathrm{NJ}$ genetic background (although this last one was not statistically significant), it is more effective to collect embryos at a 1-cell stage $(0.5 \mathrm{dpc})$ and culture to a 2-cells stage when compared to collecting embryos at a 2-cells stage $(1.5 \mathrm{dpc})$ after female's superovulation. Similar results were achieved by Van der Auwera et al. [23] that considered that the oviductal milieu after superovulation have a negative impact on embryo development when compared to a non-stimulated oviduct or to in vitro culture using B6XCBA donors and NMRI pseudopregnant females. Collecting the embryos at the 1-cell stage can significantly increase the number of embryos obtained and thus, reduce the number of animals required for this type of protocols. The effect observed on C57BL/6J, B6*129 and FVB/NJ can be related to the fact that, after superovulation, embryo development is compromised and it is possible that removal of embryos from the uterine environment decreases the negative effect of superovulation by decreasing the exposition to PMSG and hCG. Taken into account that PMSG has an half-life of 40 to $120 \mathrm{~h}$ and the half-life of hCG is about 24 - 36 hours [27], a possible explanation for our results are the lower levels of PMSG and hCG exposition once embryos 
are removed from the uterine environment and incubated in KSOM after several washes in M2. GMM strains with an FVB/NJ background didn't produce a statistically significant difference but this can be related to the smaller sample size available for this strain. Using a wild type strain such as the C57BL/6J, the same tendency of reduction in the number of 2-cells embryos when $1.5 \mathrm{dpc}$ harvesting is used was noticed. The number of 2-cells embryos collected after incubation or even at $1.5 \mathrm{dpc}$ is higher when compared to the same method using data from GMM strains at a B6 background. This can be explained by the fact that females used in the C57BL/6J experiment were all at an optimal age (3 - 4 weeks), resulting in higher number of oocytes produced after superovulation and also because this experiment resulted from only one wild type strain, having so, less variability. Nevertheless, thorough investigation will be needed to clarify the reasons why the number of 2-cells embryos is higher when incubation is used and to identify the changes observed on gene expression, lipid metabolism or the role of other essential mechanisms for embryo growth which are changed when superovulation is used and comparing it at a 1-cell and at a 2-cells stage. It would also be interesting to compare these results with embryos collected from females that are naturally mated, without superovulation. Our results are, however, compatible with those described by Van der Auwera et al. [23], reinforcing that the superovulation impact occurs not only at a later stage of development but also that the embryo reduction occurs soon after superovulation.

Genetic alterations among the strains used may also contribute to variable responses to superovulation, fertilization levels [34] [35] and incubation rates. Fertilization rates can be easily determined when embryos are collected at $0.5 \mathrm{dpc}$ by considering the total number of oocytes/1-cell embryos and allowing passage to a 2-cells stage or detecting pronucleus under the microscope. However, when the harvesting is performed at $1.5 \mathrm{dpc}$, the total number of embryos counted (including non-fertilized and fertilized embryos) is lower, as shown in Table 4, suggesting that part of the embryos might be reabsorbed during the night. For that reason, the number of 1-cell embryos/oocytes obtained at $0.5 \mathrm{dpc}$ and the number of non-fertilized embryos collected from the C57BL/6J wild type group were not compared but fertilization rates were not significantly different ( $p=0.1898$ ). This allow us to conclude that the effect observed on the reduction of the number of 2-cells when harvesting is performed at $1.5 \mathrm{dpc}$ is not related to lower fertilization rates. For the GMM strains, the number of plugs was not different among groups and the fertilization rates for the $0.5 \mathrm{dpc}$ groups was similar to the fertilization rates obtained with the wild type strains. Further data would also be needed to determine if this effect also occurs in other commonly used mouse strains.

\section{Conclusion}

Mouse superovulation can be optimized by controlling factors such as the female age, weight, dose and time of hormone administration. Our results show, that at least for the strains studied, a better planning of experiments involving the use of 
2-cells embryos through incubation technique can significantly decrease the number of females needed to obtain a specific number of embryos. Thus, when no specific stage of embryo development is required (such as for embryo transfer for rederivation or cryopreservation), harvesting embryos at $0.5 \mathrm{dpc}$ may provide a better outcome in the number of embryos than collecting embryos at 1.5 dpc (2-cells stage embryos). This practice may display a very positive impact on the reduction of animals used for superovulation contributing actively to the $3 \mathrm{R}$ 's goals.

\section{Acknowledgements}

The authors would like to thank to the i3S/IBMC facility staff for all the help provided with the animals.

\section{Conflicts of Interest}

The authors declare no conflicts of interest regarding the publication of this paper.

\section{References}

[1] Behringer, R., Gertsenstein, M., Nagy, K.V. and Nagy, A. (2018) Administration of Gonadotropins for Superovulation in Mice. Cold Spring Harbor Protocols, 2018. https://doi.org/10.1101/pdb.prot092403

[2] Luo, C., Zuñiga, J., Edison, E., Palla, S., Dong, W. and Parker-Thornburg, J. (2011) Superovulation Strategies for 6 Commonly Used Mouse Strains. Journal of the American Association for Laboratory Animal Science, 50, 471-478.

[3] Fabian, D., Babelová, J., Čikoš, Š. and Šefč́́ková, Z. (2017) Overweight Negatively Affects Outcome of Superovulation Treatment in Female Mice. Zygote, 25, 751-759. https://doi.org/10.1017/S0967199417000648

[4] Kolbe, T., Landsberger, A., Manz, S., Na, E., Urban, I. and Michel, G. (2015) Productivity of Superovulated C57BL/6J Oocyte Donors at Different Ages. Lab Animal, 44, 346-349. https://doi.org/10.1038/laban.746

[5] Inyawilert, W., Liao, Y.-J. and Tang, P.-C. (2016) Superovulation at a Specific Stage of the Estrous Cycle Determines the Reproductive Performance in Mice. Reproductive Biology, 16, 279-286. https://doi.org/10.1016/j.repbio.2016.10.004

[6] Van Keuren, M.L. and Saunders, T.L. (2004) Rederivation of Transgenic and Gene-Targeted Mice by Embryo Transfer. Transgenic Research, 13, 363-371. https://doi.org/10.1023/B:TRAG.0000040040.82536.a5

[7] González-Jara, P., Fontela, T., López-Mimbela, E., Cereceda, M., Del Olmo, D. and Moreno, M. (2017) Optimization of the Balance between Effort and Yield in Unilateral Surgical Transfer of Mouse Embryos. Lab Animal, 51, 622-628. https://doi.org/10.1177/0023677217705409

[8] Rose, C., Schwegler, H., Hanke, J. and Yilmazer-Hanke, D.M. (2012) Pregnancy Rates, Prenatal and Postnatal Survival of Offspring, and Litter Sizes after Reciprocal Embryo Transfer in DBA/2JHd, C3H/HeNCrl and NMRI Mice. Theriogenology, 77, 1883-1893. https://doi.org/10.1016/j.theriogenology.2012.01.005

[9] Besselsen, D.G., Romero-Aleshire, M.J., Munger, S.J., Marcus, E.C., Henderson, K.S. and Wagner, A.M. (2008) Embryo Transfer Rederivation of C.B-17/Icr-Prkdc(scid) Mice Experimentally Infected with Mouse Parvovirus 1. Comparative Medicine, 58, 353-359. 
[10] Amstislavsky, S.Ya., Igonina, T.N., Rozhkova, I.N., Brusentsev, E.Yu., Rogovaya, A.A., Ragaeva, D.S., Naprimerov, V.A., Litvinova, E.A., Plyusnina, I.F. and Markel, A.L. (2013) Rederivation by Embryo Transfer in Strains of Laboratory Mice and Rats. Russian Journal of Genetics. Applied Research, 3, 305-315. https://doi.org/10.1134/S2079059713040023

[11] Zhang, J., Cui, J., Ling, X., Li, X., Peng, Y., Guo, X., Heng, B.C. and Tong, G.Q. (2009) Vitrification of Mouse Embryos at 2-Cell, 4-Cell and 8-Cell Stages by Cryotop Method. Journal of Assisted Reproduction and Genetics, 26, 621-628. https://doi.org/10.1007/s10815-009-9370-2

[12] Fortier, A.L., Lopes, F.L., Darricarrère, N., Martel, J. and Trasler, J.M. (2008) Superovulation Alters the Expression of Imprinted Genes in the Midgestation Mouse Placenta. Human Molecular Genetics, 17, 1653-1665. https://doi.org/10.1093/hmg/ddn055

[13] Market-Velker, B.A., Zhang, L., Magri, L.S., Bonvissuto, A.C. and Mann, M.R.W (2009) Dual Effects of Superovulation: Loss of Maternal and Paternal Imprinted Methylation in a Dose-Dependent Manner. Human Molecular Genetics, 19, 36-51. https://doi.org/10.1093/hmg/ddp465

[14] Lee, M., Ahn, J.I., Lee, A.R., Ko, D.W., Yang, W.S., Lee, G., Ahn, J.Y. and Lim, J.M. (2017) Adverse Effect of Superovulation Treatment on Maturation, Function and Ultrastructural Integrity of Murine Oocytes. Molecules and Cells, 40, 558-566. https://doi.org/10.14348/molcells.2017.0058

[15] Wu, B.-J., Xue, H.-Y., Chen, L.-P., Dai, Y.-F., Guo, J.-T. and Li, X.-H. (2013) Effect of PMSG/hCG Superovulation on Mouse Embryonic Development. Journal of Integrative Agriculture, 12, 1066-1072. https://doi.org/10.1016/S2095-3119(13)60485-2

[16] Ozturk, S., Yaba-Ucar, A., Sozen, B., Mutlu, D. and Demir, N. (2016) Superovulation Alters Embryonic Poly(A)-Binding Protein (Epab) and Poly(A)-Binding Protein, Cytoplasmic 1 (Pabpc1) Gene Expression in Mouse Oocytes and Early Embryos. Reproduction, Fertility and Development, 28, 375-383. https://doi.org/10.1071/RD14106

[17] Ertzeid, G. and Storeng, R. (1992) Adverse Effects of Gonadotrophin Treatment on Pre- and Postimplantation Development in Mice. Journal of Reproduction and Fer tility, 96, 649-655. https://doi.org/10.1530/jrf.0.0960649

[18] Van der Auwera, I. and D'Hooghe, T. (2001) Superovulation of Female Mice Delays Embryonic and Fetal Development. Human Reproduction, 16, 1237-1243. https://doi.org/10.1093/humrep/16.6.1237

[19] Uysal, F. and Ozturk, S. (2019) Embryonic Poly(A)-Binding Protein Is Differently Expressed and Interacts with the Messenger RNAs in the Mouse Oocytes and Early Embryos. Journal of Cellular Biochemistry, 120, 4694-4709. https://doi.org/10.1002/jcb.27759

[20] Chen, X., Huang, Y., Huang, H., Guan, Y., Li, M., Jiang, X., Yu, M. and Yang, X. (2018) Effects of Superovulation, in Vitro Fertilization, and Oocyte in Vitro Maturation on Imprinted Gene Grb10 in Mouse Blastocysts. Archives of Gynecology and Obstetrics, 298, 1219-1227. https://doi.org/10.1007/s00404-018-4905-3

[21] Velker, B.A.M., Denomme, M.M., Krafty, R.T. and Mann, M.R.W. (2017) Maintenance of Mest Imprinted Methylation in Blastocyst-Stage Mouse Embryos Is Less Stable than Other Imprinted Loci Following Superovulation or Embryo Culture. Environmental Epigenetics, 3, dvx015-dvx015. https://doi.org/10.1093/eep/dvx015

[22] Karagenc, L., Yalcin, E., Ulug, U. and Bahceci, M. (2004) Administration of Increasing Amounts of Gonadotrophin Compromises Preimplantation Development 
of Parthenogenetic Mouse Embryos. Reproductive BioMedicine Online, 8, 628-634. https://doi.org/10.1016/S1472-6483(10)61642-2

[23] Van der Auwera, I., Pijnenborg, R. and Koninckx, P.R. (1999) The Influence of In-Vitro Culture versus Stimulated and Untreated Oviductal Environment on Mouse Embryo Development and Implantation. Human Reproduction, 14, 2570-2574.

https://doi.org/10.1093/humrep/14.10.2570

[24] Ertzeid, G. and Storeng, R. (2001) The Impact of Ovarian Stimulation on Implantation and Fetal Development in Mice. Human Reproduction, 16, 221-225.

https://doi.org/10.1093/humrep/16.2.221

[25] Weinerman, R., Ord, T., Bartolomei, M.S., Coutifaris, C. and Mainigi, M. (2017) The Superovulated Environment, Independent of Embryo Vitrification, Results in Low Birthweight in a Mouse Model. Biology of Reproduction, 97, 133-142. https://doi.org/10.1093/biolre/iox067

[26] Evans, M.I., Schulman, J.D., Golden, L. and Mukherjee, A.B. (1981) Superovulation-Induced Intrauterine Growth Retardation in Mice. American Journal of $\mathrm{Ob}$ stetrics \& Gynecology, 141, 433-435. https://doi.org/10.1016/0002-9378(81)90607-4

[27] Wang, L.-Y., Wang, N., Le, F., Li, L., Lou, H.-Y., Liu, X.-Z., Zheng, Y.-M., Qian, Y.-Q., Chen, Y.-L., Jiang, X.-H., Huang, H.-F. and Jin, F. (2015) Superovulation Induced Changes of Lipid Metabolism in Ovaries and Embryos and Its Probable Mechanism. PLoS ONE, 10, e0132638.

https://doi.org/10.1371/journal.pone.0132638

[28] Dorfeshan, P., Salehnia, M. and Moazzeni, S.M. (2013) Ovarian Stimulation Affects the Population of Mouse Uterine NK Cells at Early Pregnancy. BioMed Research International, 2013, Article ID: 182531. https://doi.org/10.1155/2013/182531

[29] Giritharan, G., Talbi, S., Donjacour, A., Sebastiano, F.D., Dobson, A.T. and Rinaudo, P.F. (2007) Effect of in Vitro Fertilization on Gene Expression and Development of Mouse Preimplantation Embryos. Reproduction, 134, 63-72. https://doi.org/10.1530/REP-06-0247

[30] Quéré, R., Carmignac, V., Barberet, J., Fauque, P., Guilleman, M., Bourc'his, D. and Iranzo, J. (2019) Effects of Assisted Reproductive Technologies on Transposon Regulation in the Mouse Pre-Implanted Embryo. Human Reproduction, 34, 612-622. https://doi.org/10.1093/humrep/dez020

[31] Hogan, B., Costantini, F. and Lacy, E. (1986) Manipulating the Mouse Embryo: A Laboratory Manual. Cold Spring Harbor Laboratory Press.

[32] Beaumont, H.M. and Smith, A.F. (1975) Embryonic Mortality during the Pre- and Post-Implantation Periods of Pregnancy in Mature Mice after Superovulation. Journal of Reproduction \& Infertility, 45, 437-448. https://doi.org/10.1530/jrf.0.0450437

[33] Uysal, F., Ozturk, S. and Akkoyunlu, G. (2018) Superovulation Alters DNA Methyltransferase Protein Expression in Mouse Oocytes and Early Embryos. Journal of Assisted Reproduction and Genetics, 35, 503-513. https://doi.org/10.1007/s10815-017-1087-z

[34] Golkar-Narenji, A., Gourabi, H., Eimani, H., Barekati, Z. and Akhlaghi, A. (2012) Superovulation, in Vitro Fertilization (IVF) and in Vitro Development (IVD) Protocols for Inbred BALB/cJ Mice in Comparison with Outbred NMRI Mice. Reproductive Medicine and Biology, 11, 185-192. https://doi.org/10.1007/s12522-012-0127-8

[35] Vasudevan, K., Raber, J. and Sztein, J. (2010) Fertility Comparison between Wild Type and Transgenic Mice by in Vitro Fertilization. Transgenic Research, 19, 587-594. https://doi.org/10.1007/s11248-009-9336-2 